EXTENDED REPORT

\title{
Sustained maintenance of exercise induced muscle strength gains and normal bone mineral density in patients with early rheumatoid arthritis: a 5 year follow up
}

\author{
A Häkkinen, T Sokka, H Kautiainen, A Kotaniemi, P Hannonen
}

Ann Rheum Dis 2004;63:910-916. doi: 10.1136/ard.2003.013003

See end of article for authors' affiliations

\section{Correspondence to:}

$\operatorname{Dr}$ A Häkkinen,

Department of Physical

Medicine and

Rehabilitation, Jyväskylä

Central Hospital,

Keskussairaalantie 19,

FIN-40620 Jyväskylä,

Finland;

arja.hakkinen@ksshp.fi

Accepted

28 September 2003

\begin{abstract}
Objective: To investigate at 5 years whether an initial 2 year home based strength training period imposes sustained effects on muscle strength, bone mineral density (BMD), structural joint damage, and on disease activity in patients with early rheumatoid arthritis (RA).

Methods: Seventy patients were randomised either to perform home based strength training with loads of $50-70 \%$ of repetition maximum (EG) or range of motion exercises (CG). Both groups were encouraged to take part in aerobic activities 2-3 times a week. Maximal muscle strength of different muscle groups was measured by dynamometers, and BMD at the femoral neck and lumbar spine by dual $x$ ray densitometry. Disease activity was assessed by the 28 joint disease activity score, and joint damage by $x$ ray findings. Results: 62 patients completed 2 years' training and 59 patients attended check up at 5 years. Mean (SD) maximum muscle strength indices increased from baseline to 2 years -in EG from 212 (78) kg by a mean (95\% Cl) of 68 (55 to 80 ) and in CG from 195 (72) kg by 35 (13 to 60) kg-and remained at that level for the next 3 years. Development of BMD in EG tended to be more favourable than that in CG. Muscle strength training was not detrimental to joint structures or disease activity.

Conclusion: The patients' exercise induced muscle strength gains during a 2 year training period were maintained throughout a subsequent self monitored training period of 3 years. Despite substantial training effects in muscle strength, BMD values remained relatively constant. Radiographic damage remained low even at 5 years.
\end{abstract}

$\mathrm{R}$ heumatoid arthritis (RA) interferes with physiological functions as well as structures of the musculoskeletal system-for example, by reducing muscle mass ${ }^{1}$ and strength ${ }^{2}$ and bone mineral density (BMD), ${ }^{3}{ }^{4}$ leading to a predisposition to falls and bone fractures. Osteoporosis in patients with RA is reportedly generalised and associated with decreased physical activity, ${ }^{5}$ impaired function, ${ }^{3-8}$ disease duration, ${ }^{4-11}$ and the inflammatory process itself. ${ }^{4}$ The concomitant use of corticosteroids further enhances the decrease in BMD. ${ }^{12-16}$ The vicious circle resulting in loss of muscle strength, functional capacity, and BMD in RA is finally catalysed by the inflammation associated with generalised fatigue, resulting in further limited physical activity. This forces the patients to perform their daily activities and professional duties at a higher percentage of their maximum physiological reserve. ${ }^{17}$ Conversely, a sedentary lifestyle and poorer physical fitness are associated with increased morbidity and mortality. ${ }^{18} 19$

The existing evidence for prevention of bone loss by exercise mainly concerns healthy subjects. ${ }^{20}$ Exercise appears to slow bone loss provided that it is continued for at least 1 year. ${ }^{20}$ Further, dynamic (aerobic exercise, resistance exercises, and walking) rather than static loading seems to drive skeletal adaptation. A customary loading environment with similar or repetitive loading signals is likely to make bone cells less responsive to activity. ${ }^{21-24}$ In addition to maintaining or even enhancing $\mathrm{BMD}$, physical exercises impose positive effects on muscle strength, reaction time, and coordination, reducing a person's risk for falls and bone fractures. Exercise reportedly also reduces pain, stiffness, and joint tenderness in patients with $\mathrm{RA}^{1625} 26$ and thus improves their functional capacity. ${ }^{27}{ }^{28}$ Nevertheless, although perpetual physical activity is of central importance in maintaining or increasing muscle strength in patients with RA, long term studies about the effects of strength training on muscle performance ${ }^{16}$ and BMD are few. ${ }^{16}{ }^{29}$

This randomised study aimed primarily at evaluating whether patients with early RA could maintain the gains in muscle strength obtained during an initial 2 year home based strength training period. ${ }^{16}$ Further, we focused on changes in the extent of joint damage as well as bone mineral density over the subsequent 3 year period.

\section{SUBJECTS AND METHODS \\ Subjects}

Seventy consecutive patients with recent onset RA according to the American College of Rheumatology $1987^{31}$ criteria volunteered for the 2 year study. Patients had been referred to the rheumatology unit at Jyväskylä Central Hospital for diagnosis and treatment. Their duration of symptoms was $<24$ months at inclusion, and the patients had not been treated with prednisolone or disease modifying antirheumatic drugs (DMARDs) before inclusion. Jyväskylä Central Hospital is the only rheumatological centre in the Central Finland district, which has a population of 265000 . All new RA cases are referred to the centre for diagnosis and treatment. The patients were randomly assigned either to the strength training (EG) or to the control group (CG) (table 1). The randomisation was carried out using clusters of four patients stratified according to age and sex (under and over 50 years old, female and male subjects) to ensure that the demographic data of the study groups remained

Abbreviations: $B M D$, bone mineral density; $C G$, control group; DAS, disease activity score; DMARDs, disease modifying antirheumatic drugs; EG, experimental group; HAQ, Health Assessment Questionnaire; MTX, methotrexate; RA, rheumatoid arthritis; ROM, range of motion; VAS, visual analogue scale 
comparable. During the 2 year training period two patients from the EG and three from the CG discontinued the exercises, while three patients were excluded owing to a changed diagnosis. Three years later, at the 5 year check up, 59 of the 62 patients, who completed the training period were re-examined (two patients had moved from the district and one was not interested in participating) (fig l).

\section{Training programmes}

The average stay in the rheumatology unit was 5 days for both groups. During that period, after the baseline measurements, three individual training sessions were conducted under the supervision of an experienced physiotherapist so that the strength training or conventional training programmes could be learnt properly.

\section{Strength training}

The strength training programme included exercises for all muscle groups of the arms (biceps curl, lateral pull down, forward single up-rise), legs (knee extension and flexion, hip extension and abduction, squat), and trunk (abdominal crunch and leg lifts while lying on the back, back hyperextension in prone position) using body weight, rubber bands, and dumb-bells as resistance. The training session was about 45 minutes. Subjects were instructed to exercise twice a week with moderate loads (50-70\% of the repetition maximum), two sets for each exercise, and 8-12 repetitions for each set. The intensity and technique of exercises were checked at 6, 12, 18, and 24 month follow up visits.

\section{Conventional training}

The patients in the CG were instructed to perform range of motion (ROM) and stretching exercises twice a week. Gentle ROM exercises for all joints of upper and lower extremities and neck were instructed to be performed 10 times for each exercise. The stretching exercises included active straight leg raising for hamstring muscles, stretching of quadriceps femoris muscle, calf muscles, pectoralis minor and major muscles, and biceps and triceps muscles. It was recommended that each stretching exercises should be performed with three repetitions for 30 seconds.

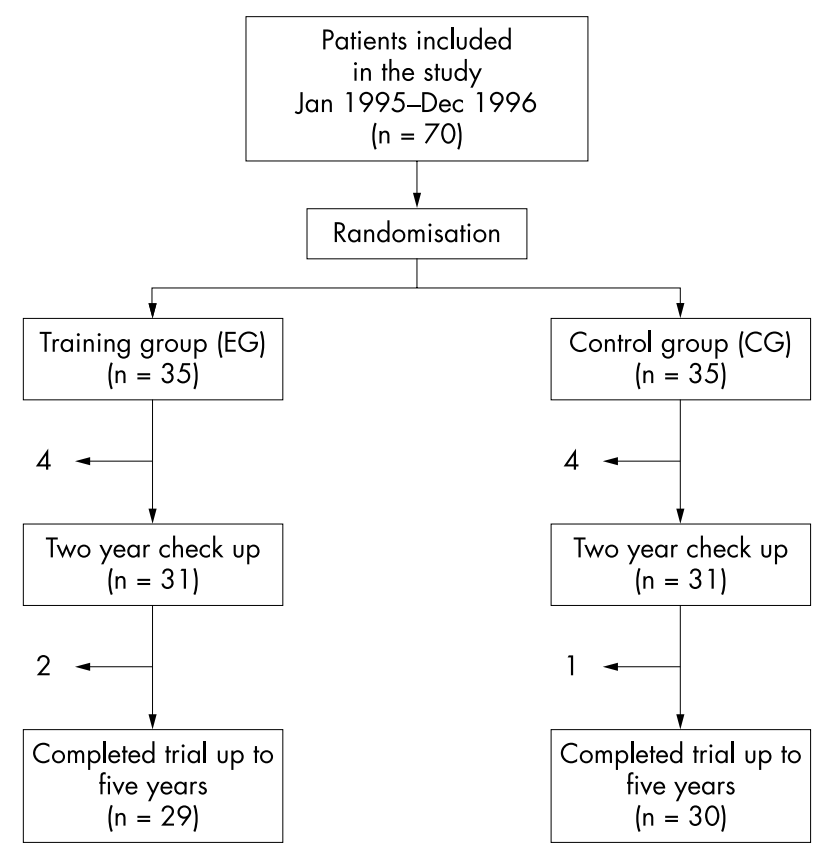

Figure 1 Trial profile.
Table 1 Baseline characteristics of experimental (EG) and control (CG) patients with early RA

\begin{tabular}{lll}
\hline Variable & EG ( $\mathbf{n = 3 1 )}$ & CG $(\mathbf{n}=\mathbf{3 1})$ \\
\hline Male:female & $13: 18$ & $11: 20$ \\
Age (years), mean (SD) & $49(10)$ & $49(11)$ \\
Body weight (kg), mean (SD) & $74(14)$ & $72(11)$ \\
Body height (cm), mean (SD) & $169(8)$ & $167(9)$ \\
Duration of symptoms (months), mean (SD) & $10(10)$ & $8(12)$ \\
Rheumatoid factor positive (n) & 19 & 19 \\
Active smokers (n) & 8 & 2 \\
\hline
\end{tabular}

After the 2 year measurements the control subjects also were instructed to carry out the strength training programme. However, the instructions for the CG patients were given only once at the outpatient clinic after the 24 month measurements without any check up visits.

In addition, all patients were encouraged to perform aerobic exercises 2-3 times a week.

\section{Assessments}

Muscle strength

The maximum unilateral concentric strength of the knee extensors was measured with the David 200 dynamometer (Outokumpu, Finland). ${ }^{32}$ For this the subject was in a sitting position with the hips fixed on a seat for a flexion position of $110^{\circ}$. The ankle was supported just above the malleoli. The load in the weight stack of the machine was gradually increased until the subject was unable to perform the full knee extension (starting from knee flexion of $110^{\circ}$ to the full extension) in order to record a subject's one repetition maximum $(\mathrm{kg})$. The maximal isometric trunk flexion and extension forces were measured by an isometric strain gauge dynamometer. ${ }^{33}$ For this the subject was in a standing position. The hips were fixed at the level of the spina iliaca anterior superior. A $5 \mathrm{~cm}$ wide strap was tightened around the shoulders at the level of the clavicle in trunk flexion and at the level of the spina scapulae in trunk extension. Isometric grip strength was measured by a Digitest dynamometer (Oulu, Finland) ${ }^{34}$ In the analysis the best absolute result of each strength measurement (knee extension, trunk extension and flexion as well as grip strength) was combined as a muscle strength index. Both groups were measured at months $0,6,12,18,24$, and at 5 years.

\section{Bone mineral density}

BMD $\left(\mathrm{g} / \mathrm{cm}^{2}\right)$ was measured in duplicate at the Rheumatism Foundation Hospital using dual $x$ ray absorptiometry bone densitometry (Lunar DPX, Lunar Radiation Corporation, Madison, WI) at months $0,12,24$, and at 5 years. The measurement sites were the lumbar vertebrae L2-4 $\left(\mathrm{BMD}_{\text {spine }}\right)$ and the left proximal femur $\left(\mathrm{BMD}_{\mathrm{fem}}\right)$. Quality assurance tests for densitometry were run daily. The precision of the method had previously been tested on adults, and the coefficient of variation (CV\%) calculated to be $1.0 \%$ for the spine and $1.8 \%$ for the femoral neck.

\section{Joint radiology}

Radiographs of hands and feet were taken at baseline, and 1 , 2 , and 5 years thereafter. The radiographs were scored according to the Larsen method. ${ }^{35}$ The II-V metatarsophalangeal joints, wrists, and metacarpophalangeal joints were assigned a score of $0-5$, with a total score of $0-100 .{ }^{36}{ }^{37}$ Joints with a score of 2 or higher were considered erosive. All the $x$ ray findings were scored simultaneously after the 5 year follow up by an experienced rheumatologist (TS) who did not know which group the patients were in. 
Functional capacity

The Finnish version of the Health Assessment Questionnaire (HAQ), scoring from 0 to 3, was used to measure functional capacity. ${ }^{38}$

\section{Clinical disease activity}

The modified 28 joint disease activity score (DAS), including the number of tender and swollen joints, patient's self reported global status (on a $0-100 \mathrm{~mm}$ visual analogue scale (VAS)), and erythrocyte sedimentation rate, were used to evaluate clinical disease activity. ${ }^{39}$ Pain, as assessed on a VAS and morning stiffness in minutes were also evaluated.

\section{Physical activity}

All subjects completed training diaries and mailed them to investigators every second month during the 2 year follow up. In addition, the type, frequency, and duration of leisure time physical activities during the past 12 months were assessed by a questionnaire at the 5 year check up visit.

\section{Statistical methods}

Results were expressed as means with standard deviations (SD) or with $95 \%$ confidence interval (95\% CI). The normality of variables was evaluated by Shapiro-Wilk statistics. Means between the groups were compared using analysis of covariance with the baseline value, age, sex, disease activity (DAS), and use of prednisolone as covariate. Spearman's correlation coefficients were calculated to assess the relationships between individual variables.

\section{RESULTS}

After initial assessments, treatment with DMARDs (sulfasalazine as the first drug with a few exceptions) was instituted in all patients. However, $24 \%$ and $50 \%$ of the patients were taking methotrexate (MTX) or a combination of DMARDs including MTX at the 6 month and 2 year visits, respectively, and the majority of the patients $(70 \%)$ were taking these drugs at the 5 year visit (figs $2 \mathrm{~A}$ and B). Three patients in both groups used no DMARDs at the 5 year visit owing to remission. Ten patients in the EG and 22 in the CG were treated with low dose prednisolone (2.5-7.5 mg/day) on average (SD) for 8.0 (7.5) months and 30.2 (23.7) months, respectively, during the 5 year follow up period. In those patients the median (interquartile range (IQR)) cumulative doses of prednisolone were $0.76(0.15-1.42) \mathrm{g}$ and $3.25(0.80$ $6.71) \mathrm{g}(\mathrm{p}=0.005)$, respectively. Further, four EG and eight CG patients received drug treatment for osteoporosis (seven patients with alendronate and one patient subsequently with salmon calcitonin, etidronate, and alendronate) for an average (SD) of 45 (1) and 31 (19) months, respectively.

The strength training compliance averaged 1.4-1.5 times a week in the EG during the 2 year training period. According to the training diaries the mean (SD) times used for various types of physical exercises (including strength training in the EG) throughout the first 2 years for the EG and CG were 245 (115) and 195 (104) minutes a week, respectively. During the 5th year the corresponding times were 237 (147) and 223 (131) minutes. Reportedly 20 EG and 12 CG patients at least occasionally practised also intensive aerobic exercises (leading to sweating and getting out of breath). Further, 10 EG but no CG cases continued with their strength training during the 5 th follow up year.

During the 2 year training period the mean (SD) maximum muscle strength indices in EG and CG increased from $212(78) \mathrm{kg}$ and from 195 (72) $\mathrm{kg}$ by a mean (95\% CI) of 68 (55 to 80$) \mathrm{kg}(32.1 \%)$ and 35 (13 to 60$) \mathrm{kg}(17.9 \%)$, respectively (table 2 ). Further, at the 5 year check up visit the respective muscle strength indices in EG and in CG were 59 (46 to 70$) \mathrm{kg}(27.8 \%)$ and 30 (13 to 46$) \mathrm{kg}(15.4 \%$ ) above the
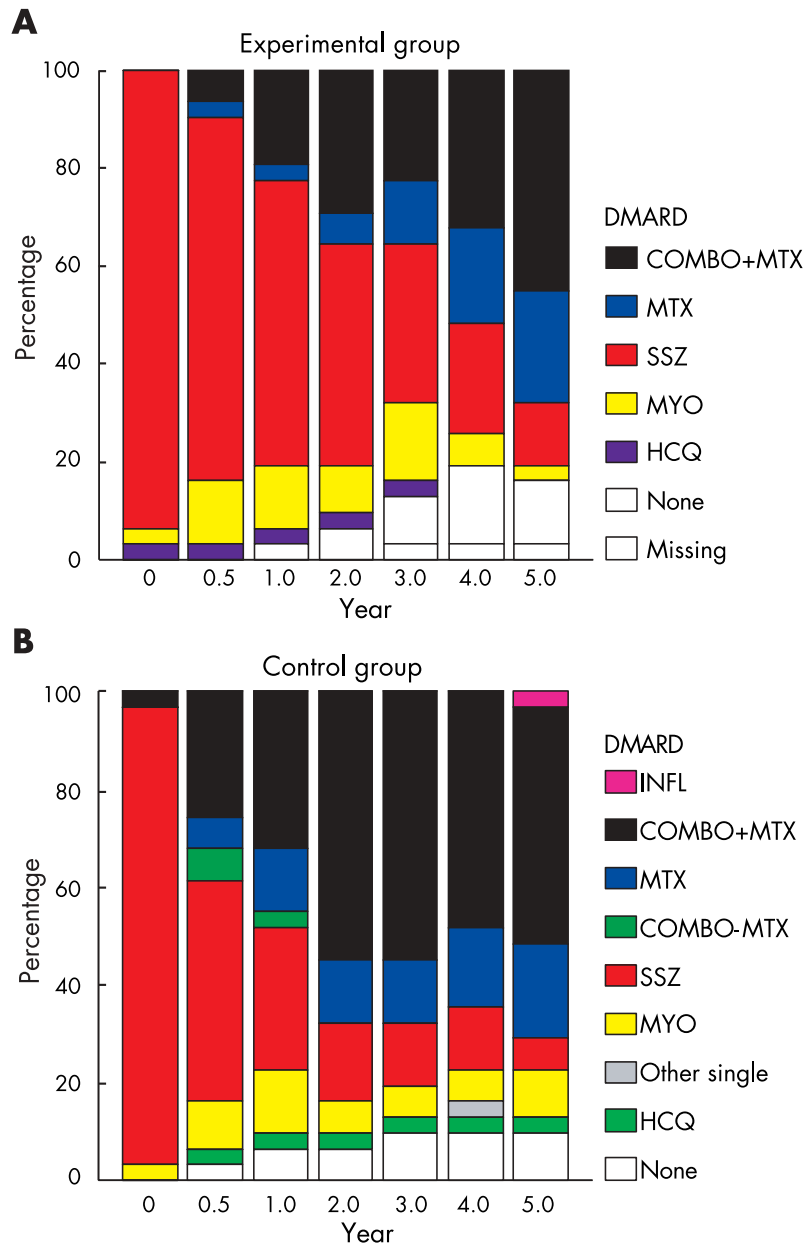

Figure 2 Disease modifying antirheumatic drugs taken by the experimental (A) and 31 control (B) patients with early RA. The percentage of patients taking each drug or combination over 5 years is shown. INFL, infliximab; COMBO+MTX, combination of DMARDs including methotrexate; DMARD, disease modifying antirheumatic drug; MTX, methotrexate; COMBO-MTX, combination of DMARDs without methotrexate; SSZ, sulfasalazine; MYO, intramuscular gold; $H C Q$, hydroxychloroquine.

baseline values. After adjustment by age, sex, disease activity (DAS), and the use of prednisolone, the differences between the groups were $p=0.050$ at 2 years and $p=0.081$ at 5 years.

Table 3 presents the absolute BMD values as well as Z scores in both measured sites. No significant intergroup differences in BMD at either of the measured sites were found at baseline (figs $3 \mathrm{~A}$ and $\mathrm{B}$ ). The mean $\mathrm{BMD}_{\mathrm{fem}}$ increased by $0.60 \%$ in EG patients, while it decreased by $1.46 \%$ in CG during the 2 year strength training period. The corresponding changes in the mean $\mathrm{BMD}_{\text {spine }}$ were $+0.96 \%$ and $-1.44 \%$ in the EG and CG, respectively. After adjustment by age, sex, disease activity (DAS), the use of prednisolone, and drug treatment for osteoporosis, the differences in $\mathrm{BMD}_{\text {spine }}(\mathrm{p}=0.65)$ and in $\mathrm{BMD}_{\text {fem }}(\mathrm{p}=0.54)$ between the groups were not significant at the 2 year check up. The respective changes at the 5 year check up from baseline were $+1.53 \% v+1.05 \%$ for $\mathrm{BMD}_{\text {spine, }}$ and $+2.12 \% v-0.45 \%$ for $\mathrm{BMD}_{\mathrm{fem}}$. After adjustment, the changes in $\mathrm{BMD}_{\text {spine }}$ $(\mathrm{p}=0.21)$ and in $\mathrm{BMD}_{\mathrm{fem}}(\mathrm{p}=0.68)$ between the groups did not reach significance. On the other hand, the observed changes of $\mathrm{BMD}_{\text {spine }}\left(r_{\mathrm{s}}=-0.28 ; \mathrm{p}=0.031\right)$ as well as $\mathrm{BMD}_{\text {fem }}\left(r_{\mathrm{s}}=-0.34 ; \mathrm{p}=0.009\right)$ correlated negatively with the cumulative dose of prednisolone in those 32 patients who 


\begin{tabular}{|c|c|c|c|}
\hline \multirow[b]{2}{*}{ Variable } & \multicolumn{2}{|l|}{ Baseline } & \multirow{2}{*}{$\begin{array}{l}\text { Difference between groups at } \\
5 \text { years } \\
\text { Mean }(95 \% \mathrm{Cl})\end{array}$} \\
\hline & $\begin{array}{l}\text { EG } \\
\text { Mean (SD) }\end{array}$ & $\begin{array}{l}\text { CG } \\
\text { Mean (SD) }\end{array}$ & \\
\hline \multicolumn{4}{|c|}{ Knee extension strength } \\
\hline Baseline & $66.0(28.8)$ & $52.4(25.1)$ & $13.6(-0.59$ to 27.4$)$ \\
\hline 2 Years & $99.9(39.7)$ & $67.7(32.8)$ & $32.2(12.7$ to 51.7$)$ \\
\hline 5 Years & 91.5 (34.4) & $68.3(36.8)$ & 23.2 (4.0 to 42.2 ) \\
\hline \multicolumn{4}{|l|}{ Grip strength } \\
\hline Baseline & $54.8(30.5)$ & $50.2(22.0)$ & $4.6(-9.2$ to 18.4$)$ \\
\hline 2 Years & $72.3(24.4)$ & $59.0(24.4)$ & $13.3(0.2$ to 26.7$)$ \\
\hline 5 Years & $73.3(25.7)$ & $61.5(25.4)$ & $11.8(-1.6$ to 25.4$)$ \\
\hline \multicolumn{4}{|c|}{ Trunk extension strength } \\
\hline Baseline & $55.9(16.9)$ & $53.7(18.4)$ & $2.2(-7.6$ to 11.8$)$ \\
\hline 2 Years & $63.4(18.2)$ & $52.3(17.6)$ & 11.1 (1.5 to 20.8 ) \\
\hline 5 Years & $60.8(15.3)$ & $52.6(19.6)$ & $8.2(-0.9$ to 17.5$)$ \\
\hline \multicolumn{4}{|c|}{ Trunk flexion strength } \\
\hline Baseline & 41.5 (13.8) & $37.5(11.0)$ & $4.0(-2.2$ to 10.3$)$ \\
\hline 2 Years & $50.3(14.0)$ & $43.1(13.9)$ & $7.2(0.1$ to 14.5$)$ \\
\hline 5 Years & $49.7(16.9)$ & $43.3(15.0)$ & $6.4(-2.1$ to 14.9$)$ \\
\hline
\end{tabular}

had been treated with the drug. In EG, the improvements in the age matched $\mathrm{Z}$ scores in $\mathrm{BMD}_{\mathrm{fem}}$, both from the baseline to 2 years $(p=0.005)$ and from baseline to 5 years $(\mathrm{p}=0.008)$, were significant.

The mean (SD) DAS decreased significantly from 4.4 (1.2) to $2.2(1.2)$ in the EG and from 4.9 (1.1) to 2.7 (1.2) in the CG during the 2 year training period. The corresponding DAS indices were $2.3(1.0)$ and 3.0 (1.2) at the 5 year check up visit. The respective improvements in HAQ during the 2 year training period in the EG and CG were from 0.59 to 0.13 and from 0.77 to 0.35 , respectively. At 5 years the HAQ values were $0.30(0.42)$ and $0.40(0.51)$, respectively. Pain decreased from 42 (19) $\mathrm{mm}$ by $67 \%$ in the EG and from 41 (27) $\mathrm{mm}$ by $39 \%$ in the CG and were $22(20) \mathrm{mm}$ and 26 (24) $\mathrm{mm}$ at 5 years. In both groups the improvements both in HAQ $(p=0.023)$ and in pain $(p=0.033)$ were in favour of the EG at 2 years. At the 5 year check up visit the significance between the groups had disappeared.

Figure 4 shows the individual values of the Larsen scores at baseline and 5 years. The respective median (IQR) Larsen scores in the EG and CG were $0(0-1), 0(0-2), 0(0-3)$, and
$0(0-3), 2(0-5), 2(0-4)$ at baseline, and at the 2 and 5 year check ups, respectively. No between-group differences were found $(\mathrm{p}=0.268)$.

\section{DISCUSSION}

This study showed that individually tailored and regularly conducted physical exercises in the early phases of the disease lead to long term increases in muscle strength in patients with RA. The patients can maintain exercise induced muscle strength gains obtained during a 2 year training period throughout a subsequent self monitored training period of 3 years. Despite substantial training effects in muscle strength, the BMD values remained relatively constant. Further, the extent of radiographic damage remained low even at 5 years, showing that patients actively treated with DMARDs can safely carry out the applied, moderate intensity physical activity.

Each activity-including activities of daily living, such as rising from a seated position or climbing stairs-requires a certain amount of strength. Many people with clinically active or with longlasting RA live just above the threshold of

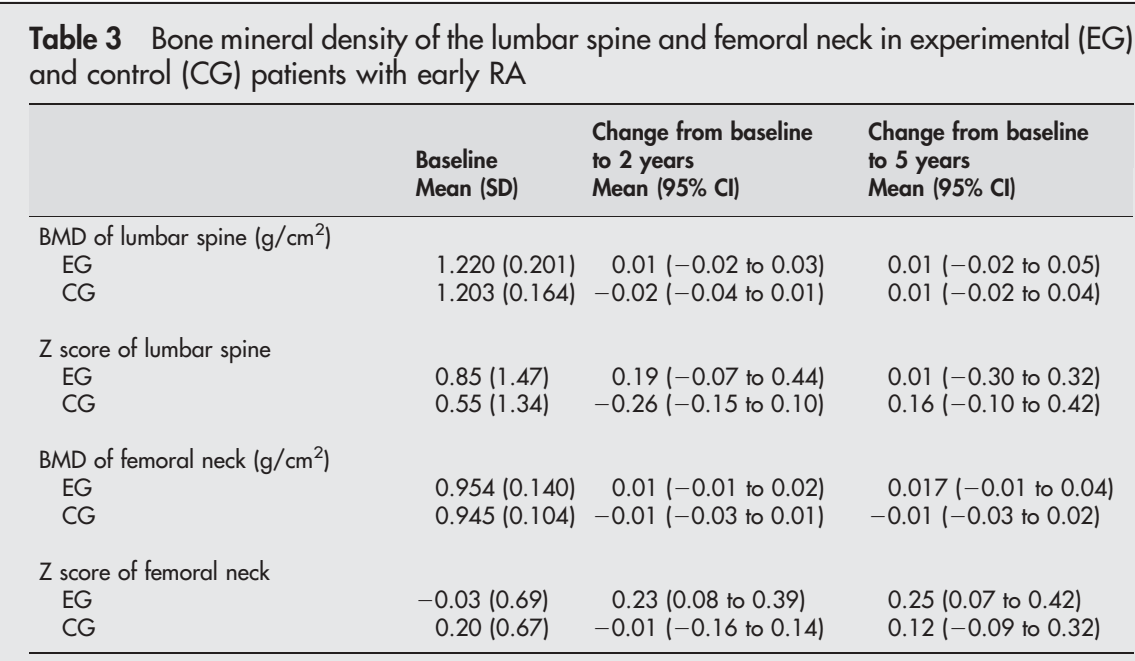



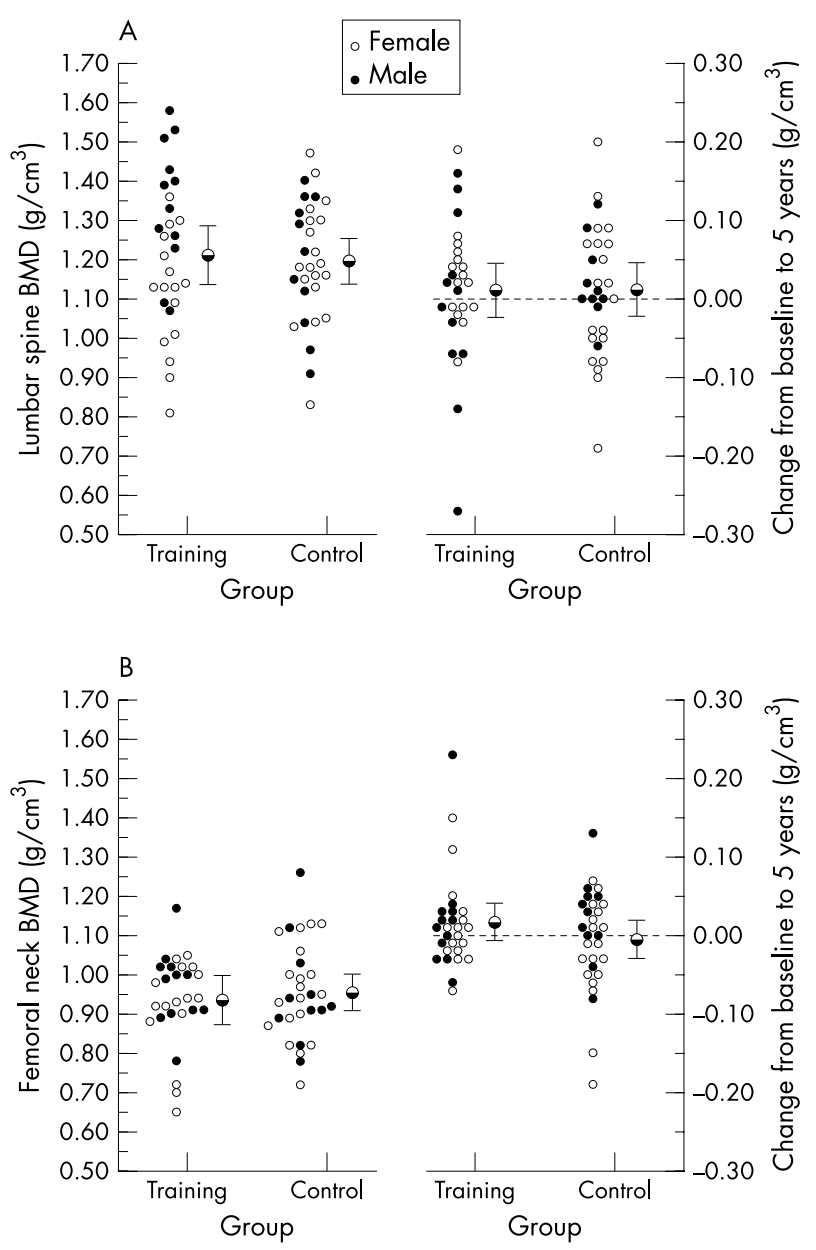

Figure 3 Bone mineral density of the lumbar spine (A) and femoral neck (B) in the experimental (EG) and control groups (CG) at baseline and after 5 years' follow up.

the capacity needed for such tasks. The reserve in performance capacity may be so slight, that even a small additional decline in strength may cause serious difficulties in performing some of the daily activities. RA is a chronic inflammatory disease, disturbing the body's metabolism and composition and favouring the loss of tissue proteins and the accretion of fat. ${ }^{1}$ Preservation of muscle strength as well as overall physical function are important elements in the prevention of disability in patients with RA. Thus, to prevent the RA induced loss of muscle strength and muscle mass, restoration and improvement of muscle reserves should be started from the very onset of the disease.

In the present study the EG patients could maintain the training induced increases in muscle strength of all measured muscle groups up to 5 years. Significant increases in muscle strength of patients with RA has also been reported. ${ }^{28}{ }^{40-43}$ In these studies the patients carried out two to five training sessions a week, but the length of the total training period was rather short, only from 3 to 24 weeks. In our study the frequency of strength training was rather low. According to the patient diaries they trained only 1.4-1.5 times a week during the first 2 years and even less thereafter. However, the loading and duration of training obviously remained sufficient to maintain the muscle strength values at the achieved level. The CG patients were encouraged also to perform ROM, stretching, and aerobic exercises. Thus, the CG patients also were able to improve their muscle strength to some extent, directly owing to a different form of exercise or indirectly

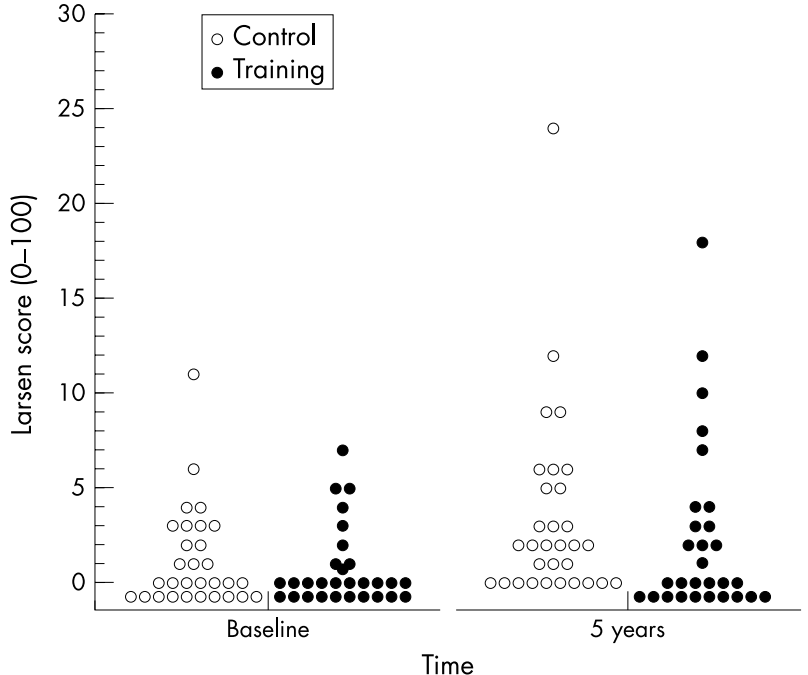

Figure 4 Individual values of the Larsen scores in experimental (EG) and control (CG) groups at baseline and after 5 years' follow up.

owing to decreased pain and disease activity. Regardless of the group to which they had initially been allotted, patients continued to use 4-5 hours a week for physical activities throughout the follow up. Further, 10 patients in the EG continued strength training also after the 2 year intervention, and $20 \mathrm{EG}$ and $12 \mathrm{CG}$ patients reportedly performed aerobic exercises with moderate intensity (sweating and getting out of breath while exercising). Thus both the type and the intensity of training in EG patients explain a substantial part of the difference in the observed muscle strengths in favour of the EG. However, we emphasise that all patients were actively treated with DMARDs and optionally also with prednisolone to keep clinical disease activity low.

Compared with healthy subjects, patients with RA are at increased risk of developing osteoporosis. ${ }^{44}{ }^{45}$ In this study most of the patients had BMD values within age matched reference values at baseline. Thus, the realistic target for the physical training was the prevention of disease related bone loss. There were no differences in the changes of absolute BMD between the groups during the 5 year follow up. However, one should note that the EG patients showed statistically significant improvements in age matched $\mathrm{Z}$ scores of $\mathrm{BMD}_{\mathrm{fem}}$ during the 2 year training as well as during the subsequent 3 year follow up period. Previous studies have provided some evidence that prolonged physical exercise delays the decrease of bone loss in healthy postmenopausal women. ${ }^{20}$ Further, Madsen et al concluded that the effect of exercise on BMD in RA is small, but it may become substantial if accumulated over a number of years. ${ }^{46}$ In addition to improving muscle strength and maintaining $\mathrm{BMD}$, physical exercise provides other benefits. It improves reaction time, balance, and coordination, and may reduce the risk of falls. ${ }^{47}$ Thus improvements in neuromuscular function and maintenance or increase in BMD would be the most adequate approach to diminish a person's risk of bone fractures. High clinical disease activity as well as glucocorticoid treatment have been recognised as the most important contributory factors to the development of osteopenia. ${ }^{4}$ In the present study, the majority of the patients treated with prednisolone as well as with antiresorptive agents were included in the CG group. The more frequent need for these drugs may reflect higher disease activity, contributing to the observed slight differences in the BMD values. On the other hand, the favourable effects of glucocorticoids on inflammation and alendronate on bone resorption apparently also 
contributed to the maintenance of their BMD at the baseline level.

Detection of joint erosions by radiography is the "gold standard" for assessing disease progress and the effectiveness of treatment in RA. Historically, dynamic exercises with intensity adequate to improve muscle strength and aerobic capacity were thought to provoke disease activity and to accelerate the development of joint damage. However, only a few earlier randomised studies have assessed the long term effects of physical exercise on radiological joint damage. ${ }^{16} 2548$ The present patients had the potential for an erosive disease. Nevertheless, the extent of radiographic damage remained low throughout the whole 5 year follow up. The most probable explanation is, that our patients were actively treated with DMARDs during the entire follow up period as depicted in fig $1 .{ }^{30}$ Furthermore, the efficacy as well as the safety of the treatment was confirmed with regular clinical assessments and laboratory tests by a rheumatologist. Luukkainen et al showed a quarter of a century ago that radiographic damage in patients with RA can be retarded over 5 years with early and active treatment with intramuscular gold. ${ }^{48}$ Recent results of two randomised clinical trials confirm the benefits of early and active treatment on the development of joint destruction in early RA over a 5 year period..$^{40}$ Thus, active treatment with DMARDs helps the patients with RA to use continuous dynamic exercise treatment without detrimental effects on joints. Also, the other measures of clinical disease activity confirmed the safety of active training with the premises applied.

One limitation of the study was that the patients in the CG required more active treatment-for example, with prednisolone and with antiresorptive drugs. Thus, it is impossible to unambiguously conclude that the strength changes seen are solely due to the exercise intervention. A strength of the study was that the rheumatologist who assessed the clinical status and $x$ ray findings of the patients did not know which group the patients were in. On the other hand, the physiotherapists were not "blinded". An advantage of the study is that it was performed, and provides long term evidence, in a real clinical setting. In contrast, most of the earlier short term studies were carried out in expensive laboratory settings, but we used low tech and low cost systems that allow patients with RA to exercise at home.

In conclusion, individually tailored and regularly conducted physical exercises provide long term benefits for patients with early RA. Structural joint damage remained low and clinical disease activity decreased during the whole 5 year follow up, indicating that patients actively treated with DMARDs can safely carry out the applied, individually tailored, moderate intensity physical activity.

\section{ACKNOWLEDGEMENT}

This study was supported by a grant from the Central Finland Health Care District.

\section{Authors' affiliations}

A Häkkinen, Department of Physical Medicine and Rehabilitation, Jyväskylä Central Hospital, Jyväskylä, Finland

T Sokka, P Hannonen, Department of Medicine, Jyväskylä Central Hospital, Jyväskylä, Finland

T Sokka, Vanderbilt University Medical Centre, Nashville, USA

H Kautiainen, A Kotaniemi, Rheumatism Foundation Hospital, Heinola, Finland

\section{REFERENCES}

Roubenoff R. Exercise and inflammatory disease. Arthritis Rheum 2003:15:263-6.

2 Ekdahl C, Broman G. Muscle strength, endurance, and aerobic capacity in rheumatoid arthritis: a comparative study with healthy subjects. Ann Rheum Dis 1992;51:35-40.
3 Gough A, Lilley J, Ayre S, Holder R, Emery P. Generalized bone loss patients with early rheumatoid arthritis. Lancet 1994;344:23-7.

4 Laan R, Buijs W Verbeek A, Draad M, Corstens L, van de Putte L, van Riel P. Bone mineral density in patients with recent onset rheumatoid arthritis: influence of disease activity and functional capacity. Ann Rheum Dis 1993;52:21-6.

5 Sambrook P, Eisman J, Champion G, Yeates M, Pocock N, Eberl S. Determinants of axial bone loss in rheumatoid arthritis. Arthritis Rheum 1987;30:721-8.

6 Hansen M, Florescu A, Stoltenberg M, Podenphant J, Pedersen-Zbinden B, Horslev-Petersen K, et al. Bone loss in rheumatoid arthritis. Influence of disease activity, duration of the disease, functional capacity, and corticosteroid treatment. Scand J Rheumatol 1996;25:367-76.

7 Eggelmeijer F, Camps J, Valkema R, Papapoulos S, Pauwels B, Dijkmans B, et al. Bone mineral density in ambulant, non-steroid treated female patients with rheumatoid arthritis. Clin Exp Rheumatol 1993;11:381-5

8 Kröger H, Honkanen R, Saarikoski S, Alhava E. Decreased axial bone mineral density in perimenopausal women with rheumatoid arthritis. A population based study. Ann Rheum Dis, 1994;53:18-23.

9 Celiker R, Gökce-Kutsal Y, Cindas A, Ariyurek M, Renda N, Koray Z, et al. Osteoporosis in rheumatoid arthritis: effect of disease. Clin Rheumatol 1995; 14:429-33.

10 Haugeberg G, Uhlig T, Falch JA, Halse JI, Kvien TK. Bone mineral density and frequency of osteoporosis in female patients with rheumatoid arthritis: results from 394 patients in the Oslo County Rheumatoid Arthritis register. Arthritis Rheum 2000;43:522-30.

11 Martin JC, Munro R, Campbell MK, Reid DM. Effects of disease and corticosteroids on apendicular bone mass in postmenopausal women with rheumatoid arthritis: comparison with axial measurements. $\mathrm{Br} J$ Rheumatol 1997;36:43-9

12 Sambrook P, Cohen M, Eisman J, Pocock N, Champion G, Yeates M. Effects of low-dose corticosteroids on bone mass in rheumatoid arthritis: longitudinal study. Ann Rheum Dis 1989;48:535-8.

13 Rothstein J, Delitto A, Sinacore D, Rose S. Muscle function in rheumatic disease patients treated with corticosteroids. Muscle Nerve 1983;6:128-35.

14 Butler RC, Davie MWJ, Worsfold M, Sharp CA. Bone mineral content in patients with rheumatoid arthritis: relationship to low-dose steroid therapy. Br J Rheumatol 1991;30:86-90.

15 Buckley LM, Leib ES, Cartularo KS, Vacek PM, Cooper SM. Effects of low dose corticosteroids on the bone mineral density of patients with rheumatoid arthritis. J Rheumatol 1995;22:1055-9.

16 Hakkinen A, Sokka T, Kotaniemi A, Hannonen P. A randomized two-year study of the effects of dynamic strength training on muscle strength, disease activity, functional capacity, and bone mineral density in early rheumatoid arthritis. Arthritis Rheum 2001:44:515-22.

17 Grady M, Flether J, Ortiz S. Therapeutic and physical fitness exercise prescription for older adults with joint disease: An evidence-based approach. Rheum Dis Clin North Am 2000;26:617-46.

18 Bacon PA, Townend JN. Nails in the coffin: increasing evidence for the role of rheumatic disease in the cardiovascular mortality of rheumatoid arthritis. Arthritis Rheum 2001;44:2707-10.

19 Del Rincon ID, Wiliams K, Stern MP, Escalante A. High incidence of cardiovascular events in a rheumatoid arthritis cohort not explained by traditional cardiac risk factors. Arthritis Rheum 2001;44:2737-45.

20 Bonaiuti D, Shea B, lovine R, Negrini S, Robinson V, Kemper HC, et al. Exercise for preventing and treating osteoporosis in postmenopausal women (Cochrane review). In: Cochrane Library, Issue 2. Oxford: Update Software, 2002.

21 Lohman T, Going S, Pamenter R, Hall M, Bouden T, Houtcooper L, et al. Effects of resistance training on regional and total bone mineral density in premenopausal women. A randomized prospective study. J Bone Miner Res 1995; 10:1015-24.

22 Heinonen A, Sievänen $H$, Kannus $P, O j a$ P, Vuori I. Effects of unilateral strength training and detraining on bone mineral mass and estimated mechanical characteristics of the upper limb bones in young women. J Bone Miner Res 1996;11:490-501.

23 Wallace BA, Cumming RG. Systematic review of randomized trials of the effect of exercise on bone mass in pre- and postmenopausal women. Calcif Tissue Int 2000:67:10-18.

24 Kelley GA, Kelley KS, Tran ZV. Resistance training and bone mineral density in women: a meta-analysis of controlled trials. Am J Phys Med Rehabil 2001;80:65-77.

25 Stenstrom CH. Radiologically observed progression of joint destruction and its relationship with demographic factors, disease severity, and exercise frequency in patients with rheumatoid arthritis. Phys Ther 1994;74:32-9.

26 Komatireddy G, Leitch R, Cella K, Browning G, Minor M. Efficacy of low load resistive muscle training in patients with rheumatoid arthritis functional class II and III. J Rheumatol 1997:24:1531-9.

27 Munneke M, de Jong Z, Zwinderman AH, Tijhuis GJ, Hazes JM, Vliet Vlieland TP. The value of a continuous ambulatory activity monitor to quantify the amount and intensity of daily activity in patients with rheumatoid arthritis. $J$ Rheumatol 2001;28:745-50.

28 Van den Ende CH, Breedveld FC, le Cessie S, Dijkmans BA, de Mug AW, Hazes JM. Effect of intensive exercise on patients with active rheumatoid arthritis: a randomised clinical trial. Ann Rheum Dis 2000;59:615-21.

29 Westby M, Wade J, Rangno K, Berkowitz J. A randomized controlled trial to evaluate the effectiveness of an exercise program in women with rheumatoid arthritis taking low dose prednisolone. J Rheumatol 2000;27:1674-80.

30 Sokka T, Hannonen P. Utility of disease modifying antirheumatic drugs in "saw tooth" strategy. A prospective study of early rheumatoid arthritis patients up to 15 years. Ann Rheum Dis 1999;58:618-22. 
31 Arnett FC, Edworthy SM, Bloch DA, McShane DJ, Fries JF, Cooper NS, et al. The American Rheumatism Association 1987 revised criteria for the classification of rheumatoid arthritis. Arthritis Rheum 1998;31:315-24.

32 Häkkinen K, Komi P, Kauhanen $\mathrm{H}$. Scientific evaluation of specific loading of the knee extensors with variable resistance, isokinetic and barbell exercises. In: Marconnet P, Komi P, eds. Medicine and sport science. Basel: Kargel, 1987:224-37.

33 Rantanen $\mathbf{P}$, Airaksinen $\mathrm{O}$, Penttinen E. Paradoxical variation of strength determinants with different rotation axes of trunk flexion and extension strength tests. Eur J Appl Physiol 1994;68:322-6.

34 Mathiowetz V, Candidate PD. Reliability and validity of grip and pinch strength measurements. Phys Rehabil Med 1991;4:201-12.

35 Larsen A, Dale K, Eek M. Radiographic evaluation of rheumatoid arthritis and related conditions by standard reference films. Acta Radiol [Diagn] (Stockh) 1977; 18:481-91.

36 Larsen A. How to apply Larsen score in evaluating radiographs of rheumatoid arthritis in longterm studies? J Rheumatol 1995;22:1974-5.

37 Kaarela K, Kautiainen $\mathrm{H}$. Continuous progression of radiological destruction in seropositive rheumatoid arthritis. J Rheumatol 1997:24:1285-7.

38 Fries JF, Spitz P, Kraines RG, Holman HR. Measurement of patient outcome in arthritis. Arthritis Rheum 1980;23:137-45.

39 Prevoo M, van ' $t$ Hof $M$, Kuper H, van Leeuwen M, van de Putte L, van Riel P. Modified disease activity scores that include twenty-eight-joint counts. Arthritis Rheum 1995;38:44-8.

40 Lyngberg KK, Ramsing BU, Nawrocki A, Harreby M, Danneskiold-Samsoe B. Safe and effective isokinetic knee extension training in rheumatoid arthritis. Arthritis Rheum 1994;37:623-8.

41 McMeeken J, Stillman B, Story I, Kent P, Smith J. The effects of knee extensor and flexor muscle training on the timed up-and-go test in individuals with rheumatoid arthritis. Physiother Res Int 1999;4:55-67.
42 Rall L, Meydani S, Kehayias J, Dawson-Hughes B, Roubenoff R. The effect of progressive resistance training in rheumatoid arthritis. Arthritis Rheum 1996;39:415-26

43 Komatireddy G, Leitch R, Cella K, Browning G, Minor M. Efficacy of low load resistive muscle training in patients with rheumatoid arthritis functional class II and III. J Rheumatol 1997;24:1531-9.

44 Kroot EJ, Nieuwenhuizen MG, de Waal Malefijt MC, van Riel PL, Pasker-de Jong PC, Laan RF. Change in bone mineral density in patients with rheumatoid arthritis during the first decade of the disease. Arthritis Rheum 2001;44:1254-60.

45 Dolan A, Moniz C, Abraha H, Pitt P. Does active treatment of rheumatoid arthritis limit disease-associated bone loss? Rheumatology (Oxford) 2002:41:1047-51.

46 Madsen OR, Sorensen $\mathrm{OH}$, Egsmose $\mathrm{C}$. Bone quality and bone mass as assessed by quantitative ultrasound and dual energy $x$-ray absorptiometry in women with rheumatoid arthritis: relationship with quadriceps strength. Ann Rheum Dis 2002;61:325-9.

47 Rantanen T. Muscle strength, disability and mortality. Scand J Med Sci Sports 2003;13:3-8.

48 Luukkainen $\mathrm{R}$, Kajander $\mathrm{A}$, Isomaki $\mathrm{H}$. Effect of gold on progression of erosions in rheumatoid arthritis: better results with early treatment. Scand J Rheumatol 1977;6:189-92.

49 Korpela M Mottonen T, Laasonen L, Kautiainen H, Hannonen P, LeirisaloRepo M. The impact of intial aggressive drug treatment with DMARDs on the development of joint damage in the long term in patients with rheumatoid arthritis (RA). The 5-year experience from the FIN-RACo study [abstract]. Arthritis Rheum 2001;44(suppl):S153.

50 Landewe RB, Boers M, Verhoeven AC, Westhovens R, van De Laar MA, Markusse $\mathrm{HM}$, et al. COBRA combination therapy in patients with early rheumatoid arthritis: long-term structural benefits of a brief intervention. Arthritis Rheum 2002;46:347-56. 